\title{
Antinociceptive Properties of Physalins from Physalis angulata
}

\author{
Milena da Silva Lima, ${ }^{\dagger}$ Afrânio Ferreira Evangelista, ${ }^{\ddagger}$ Gisele Graça Leite dos Santos, ${ }^{\ddagger}$ Ivone Maria Ribeiro, ${ }^{\S}$ \\ Therezinha Coelho Barbosa Tomassini, ${ }^{\S}$ Milena Botelho Pereira Soares, ${ }^{\ddagger}, \perp$ and \\ Cristiane Flora Villarreal $*^{\dagger, \dagger}$ \\ ${ }^{\dagger}$ Faculdade de Farmácia, Universidade Federal da Bahia, CEP 40170-290, Salvador, BA, Brazil \\ ${ }^{*}$ Centro de Pesquisas Gonçalo Moniz, Fundação Oswaldo Cruz, CEP 40296-710, Salvador, BA, Brazil \\ ${ }^{\S}$ FarManguinhos, Fundação Oswaldo Cruz, CEP 22775-903, Rio de Janeiro, RJ, Brazil \\ ${ }^{\perp}$ Centro de Biotecnologia e Terapia Celular, Hospital São Rafael, CEP 41253-190, Salvador, BA, Brazil
}

ABSTRACT: Pain is the most common reason a patient sees a physician. Nevertheless, the use of typical painkillers is not completely effective in controlling all pain syndromes; therefore further attempts have been made to develop improved analgesic drugs. The present study was undertaken to evaluate the antinociceptive properties of physalins B (1), D (2), F (3), and G (4) isolated from Physalis angulata in inflammatory and centrally mediated pain tests in mice. Systemic pretreatment with 1-4 produced dose-related antinociceptive effects on the writhing and formalin tests, traditional screening tools for the assessment of analgesic drugs. On the other hand, only 3 inhibited inflammatory parameters such as hyperalgesia,
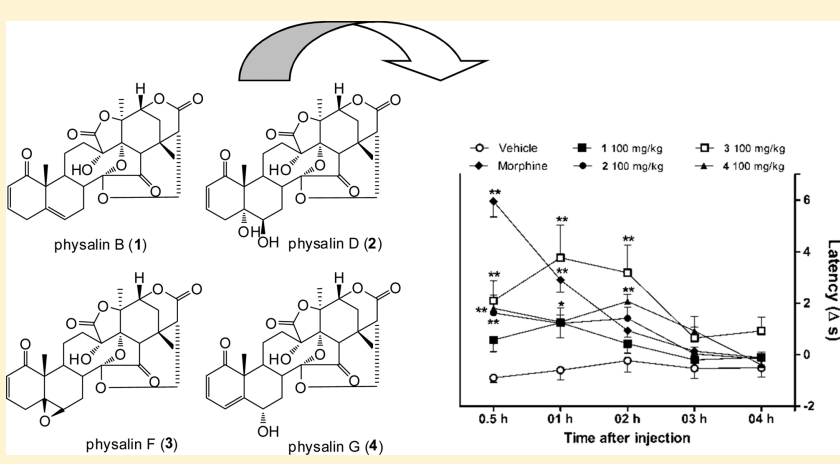
edema, and local production of TNF- $\alpha$ following induction with complete Freund's adjuvant. Treatment with 1, 3, and 4 produced an antinociceptive effect on the tail flick test, suggesting a centrally mediated antinociception. Reinforcing this idea, 2-4 enhanced the mice latency reaction time during the hot plate test. Mice treated with physalins did not demonstrate motor performance alterations. These results suggest that 1-4 present antinociceptive properties associated with central, but not anti-inflammatory, events and indicate a new pharmacological property of physalins.

$\mathrm{P}$ ain is an unpleasant feeling often caused by intense or damaging stimuli, which serves as a warning mechanism that indicates imminent tissue damage. Chronic pain lacks such protective function, since it persists for years without reflecting the severity of a lesion or disease. ${ }^{1}$ Pain is the most common reason a patient sees a physician. ${ }^{2}$ It is a major symptom in many medical conditions, and despite the enormous morbidity and damaging effect on quality of life, pain management has limited therapeutic success, which may be due, at least in part, to the small range of useful drugs. ${ }^{3,4}$ The main drugs currently used for the control of pain include nonsteroidal anti-inflammatory drugs (NSAIDs), antidepressants, anticonvulsants, and opioids. ${ }^{5-8}$ Nevertheless, the use of typical painkillers is not completely effective in controlling all pain syndromes; therefore further attempts have been made to develop improved analgesic drugs. ${ }^{9}$ In fact, pharmacotherapy provides clinically expressive pain relief in no more than $50 \%$ of patients suffering from neuropathic pain, and the pain relief is almost always associated with side effects including cardiac toxicity, nausea, sedation, and physical dependence. $^{10-12}$

Physalis angulata (Solanaceae) is a widespread indigenous herb found in areas of Africa, Asia, and the Americas, widely used in popular medicine as an analgesic and antirheumatic and to treat sore throats and abdominal pain. ${ }^{13}$ Pharmacological studies have shown that $P$. angulata presents consistent anti-inflammatory, antinociceptive, and immunomodulatory properties. ${ }^{14-16}$ Physalins are steroid derivatives isolated from Physalis spp. with potent anti-inflammatory and immunomodulatory activities. ${ }^{17-21}$ These molecules prevent mortality induced by a lethal injection of lipopolysaccharide (LPS) and inhibit rejection of allogeneic transplants in mice. ${ }^{17,18}$ The anti-inflammatory activity of physalins was also demonstrated in models of intestinal ischemia and reperfusion injury, dermatitis, and arthritis. ${ }^{22,20,23}$ In addition, physalins inhibit NF-kappaB activation, a key inflammatory transcription factor, and the production of proinflammatory mediators, such as tumor necrosis factor (TNF)-alpha, interleukin-6, and interleukin-12. ${ }^{21,17}$

Currently, there is an enhanced interest in the development of disease-modifying drugs. It is well accepted that cytokines constitute a link between cellular injuries and signs of inflammation. ${ }^{24-26}$ In contrast to NSAIDs, inhibitors of cytokine production can exhibit disease-modifying activities, representing an improved therapeutic strategy for the control of inflammatory pain. ${ }^{27}$ Therefore, in the present study, using inflammatory pain models and nociceptive tests, the antinociceptive properties of

Received: May 9, 2014

Published: November 14, 2014 
physalins B (1), D (2), F (3), and G (4) from P. angulata were evaluated.

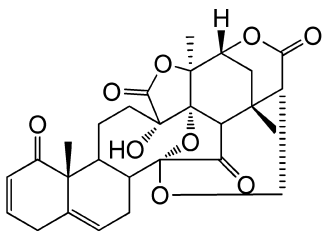

physalin B (1)

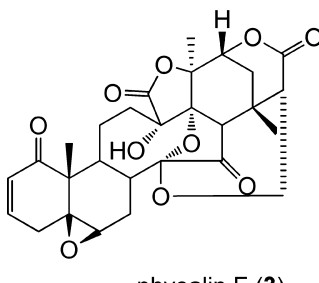

physalin $\mathrm{F}(3)$
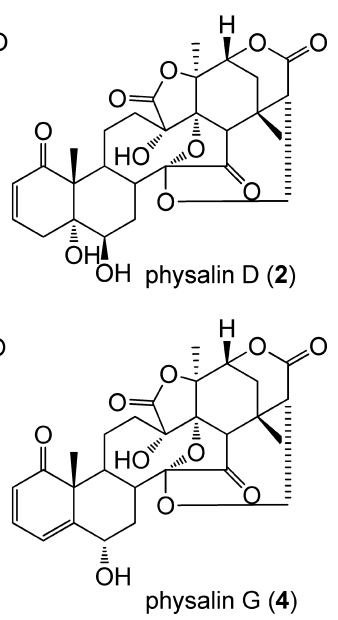

\section{RESULTS AND DISCUSSION}

The present study demonstrated for the first time that systemic administration of $\mathbf{1 - 4}$, at a dose that did not induce motor performance alteration, produced consistent antinociceptive effects. The data analysis from inflammatory pain models and centrally mediated nociceptive tests suggests that the antinociceptive properties of physalins are not a result of its known anti-inflammatory effect, but may be associated with a blockade of neural pain transmission, such as that described in morphine. ${ }^{28}$ These results identify a new pharmacological property of physalins.

The antinociceptive properties of $1-4$ were initially evaluated using the writhing test in mice, a screening tool for the assessment of analgesic or anti-inflammatory properties of new substances. ${ }^{29}$ Intraperitoneal (ip) administration of 1, 2, and 4 (50 and $100 \mathrm{mg} / \mathrm{kg}$ ) $40 \mathrm{~min}$ before acid injection produced a significant and dose-related inhibition of acetic acid-induced abdominal constrictions in mice (Figure 1A, B, and D, respectively). In addition, ip administration of 3 inhibited abdominal constrictions in mice, also at the dose of $25 \mathrm{mg} / \mathrm{kg}$ (Figure 1C). Indomethacin $(10 \mathrm{mg} / \mathrm{kg}$, ip), a standard NSAID used as positive control, produced a significant inhibition of the writhing test response. The acetic acid-induced writhing in mice has long been used as a screening tool for the assessment of new analgesic drugs. $^{29}$ This method is used due to its strong sensitivity; however it lacks in demonstrating specificity. To avoid misinterpretation of the results, in the present study the antinociceptive effects of $\mathbf{1 - 4}$ were confirmed using the formalin test, a model of pain with two distinctive phases that may indicate different types of pain. ${ }^{30}$ The early phase (nociceptive) is a result of direct stimulation of nociceptors, and the late phase (inflammatory pain) is caused by local inflammation with a release of hyperalgesic mediators. ${ }^{30}$ Injection of formalin in control animals induced a biphasic flinching response, with the early phase ranging from 0 to $10 \mathrm{~min}$ (Figure $2 \mathrm{~A}, \mathrm{C}, \mathrm{E}$, and $\mathrm{G}$ ) and the late phase from 10 to $30 \mathrm{~min}$ (Figure $2 \mathrm{~B}, \mathrm{D}, \mathrm{F}$, and $\mathrm{H}$ ) after the injection. Treatment with 1 and 2 (25, 50, and $100 \mathrm{mg} / \mathrm{kg}$, ip), $40 \mathrm{~min}$ before the injection of formalin, caused an antinociceptive effect in the late phase of this test (Figure 2B and $\mathrm{D}$, respectively). Intraperitoneal administration of 3 (50 and $100 \mathrm{mg} / \mathrm{kg}$; Figure 2E and F) and 4 (50 mg/kg; Figure 2G and H) $40 \mathrm{~min}$ before the injection of formalin caused antinociceptive effects in both the early and late phases of this test. The pretreatment with indomethacin $(10 \mathrm{mg} / \mathrm{kg}$, ip) inhibited the late phase, while the pretreatment with morphine $(5 \mathrm{mg} / \mathrm{kg}$, ip), a gold standard opioid, inhibited both the early and late phases of the formalin
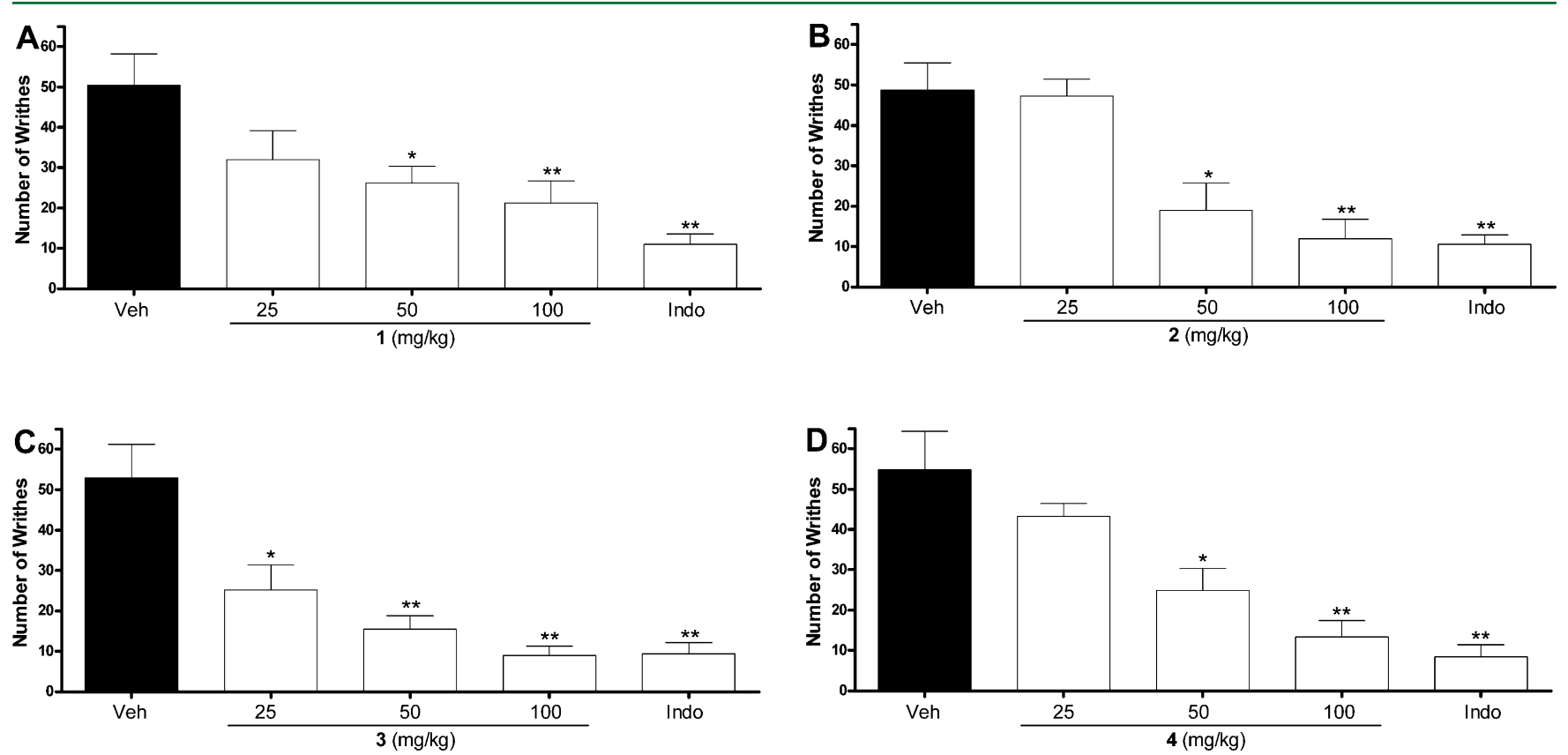

Figure 1. Effects of intraperitoneal administration of 1-4 on acetic acid-induced writhing in mice. Mice were treated with $1(25-100 \mathrm{mg} / \mathrm{kg}, \mathrm{panel} \mathrm{A}), 2$ (25-100 mg/kg, panel B), 3 (25-100 mg/kg, panel C), 4 (25-100 mg/kg, panel D), vehicle (Veh; control group), or indomethacin (Indo, $10 \mathrm{mg} / \mathrm{kg}$; reference drug) by intraperitoneal route $40 \mathrm{~min}$ before the intraperitoneal administration of acetic acid $0.8 \%$ (injected at time zero). Writhing scores were tabulated for over a $30 \mathrm{~min}$ period beginning immediately after acetic acid administration. Data are expressed as mean writhing scores $\pm \mathrm{SEM} ; n=$ 10 mice per group. *Significantly different from control group $(p<0.05)$; **significantly different from control group $(p<0.01)$, as determined by ANOVA followed by Tukey's test. 

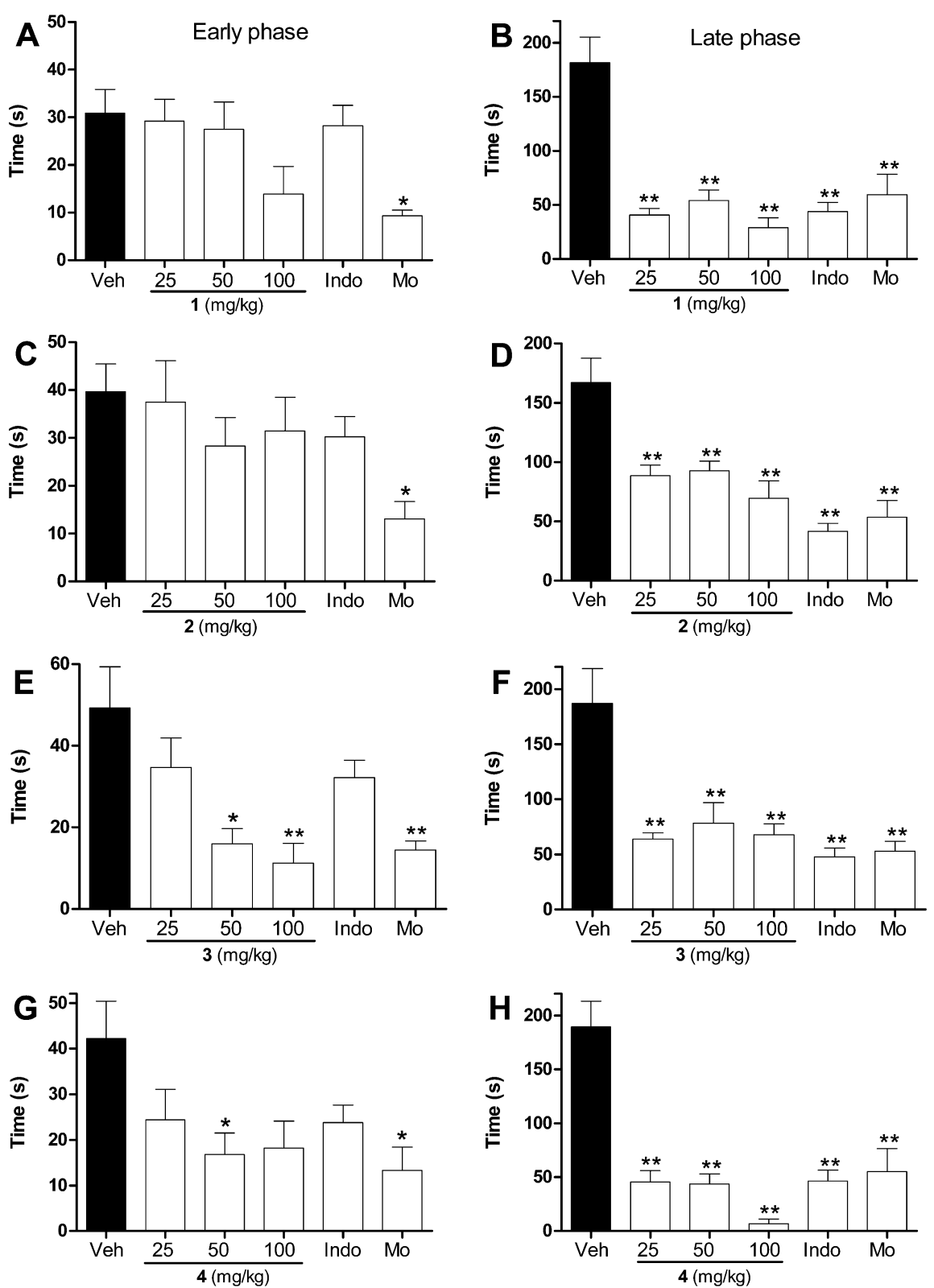

Figure 2. Effects of intraperitoneal administration of 1-4 on the formalin test in mice. Mice were treated by intraperitoneal route 40 min before the intraplantar injection of formalin (injected at time zero). Veh: vehicle. Indo: indomethacin $(10 \mathrm{mg} / \mathrm{kg})$. Mo: morphine $(5 \mathrm{mg} / \mathrm{kg})$. Mice were observed from 0 to $10 \mathrm{~min}$ (early phase) and from 10 to $30 \mathrm{~min}$ (late phase), and a nociception score was determined for each period by counting the time that the animal spent licking the injected limb during the observation time. Data are expressed as mean times \pm SEM; $n=7-10$ mice per group. *Significantly different from control group $(p<0.05)$; **significantly different from control group $(p<0.001)$, as determined by ANOVA followed by Tukey's test.

test (Figure 2). Moreover, relaxing or motor deficit effects were discarded, since administration of $\mathbf{1 - 4}$ at antinociceptive doses did not affect the motor performance in mice, as assessed by the rota-rod (Figure 3A) and open-field (Figure 3B) tests. As expected, the central nervous system depressant diazepam $(10 \mathrm{mg} / \mathrm{kg}$, ip) reduced the duration that mice were able to remain on the rota-rod, as well as the number of open-field crossings, after $40 \mathrm{~min}$ of treatment with this standard drug. These results corroborate the antinociceptive effect of physalins, as suggested by the pain models.

Considering the well-described anti-inflammatory properties of physalins, it may be suggested that their antinociceptive activity is due, at least in part, to an anti-inflammatory action. ${ }^{17,20-23}$ In an attempt to verify the relationship between the antinociceptive and anti-inflammatory properties of these compounds, the effects of treatment with 1-4 were assessed in an experimental protocol used for screening new antiinflammatory drugs: the complete Freund's adjuvant (CFA)induced paw inflammation model. CFA, which consists of heatkilled mycobacteria suspended in a mineral oil vehicle, produces a chronic inflammatory condition when injected into rodents. It is well recognized that the injection of CFA produces inflammation initiated by a local release of mediators, such as cytokines and prostanoids, which are involved in the inflammatory signs, such as edema, hyperalgesia, and vasodilation. $^{26,31-34}$ Therefore, in the present study the effects of physalins on inflammatory hyperalgesia, paw edema, and local levels of cytokines induced by CFA were evaluated. Administration of 3 at $100 \mathrm{mg} / \mathrm{kg}$ by ip route, $40 \mathrm{~min}$ before CFA, significantly reduced inflammatory hyperalgesia at $2 \mathrm{~h}$, but not at 

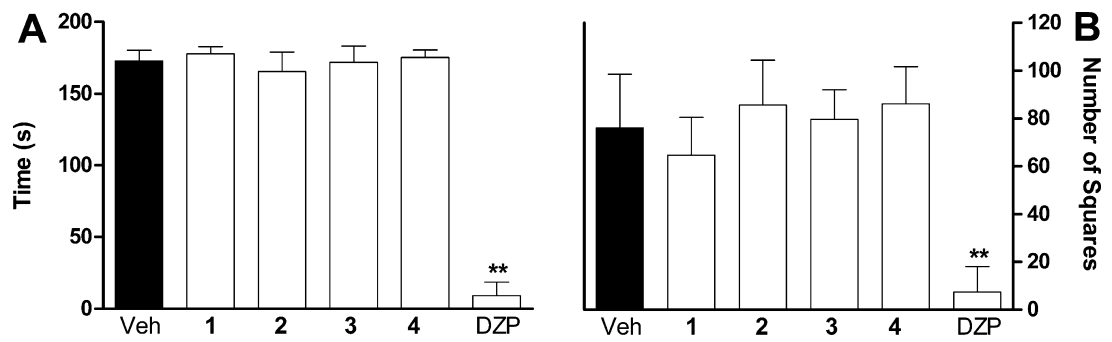

Figure 3. Effects of 1-4 treatment on motor function in mice. Bar graphs representing (A) the run time on the rota-rod and (B) the number of square crossings in the open-field test, $40 \mathrm{~min}$ after ip injection of 1, 2, 3, 4 (each at $100 \mathrm{mg} / \mathrm{kg}$ ), diazepam (DZP; $10 \mathrm{mg} / \mathrm{kg}$ ), or vehicle (Veh, 5\% DMSO in saline; control group). Data are reported as means \pm SEM; $n=6$ mice per group. ${ }^{* * S i g n i f i c a n t l y ~ d i f f e r e n t ~ f r o m ~ t h e ~ c o n t r o l ~ g r o u p ~}(p<0.001)$. One-way ANOVA followed by the Tukey's test.
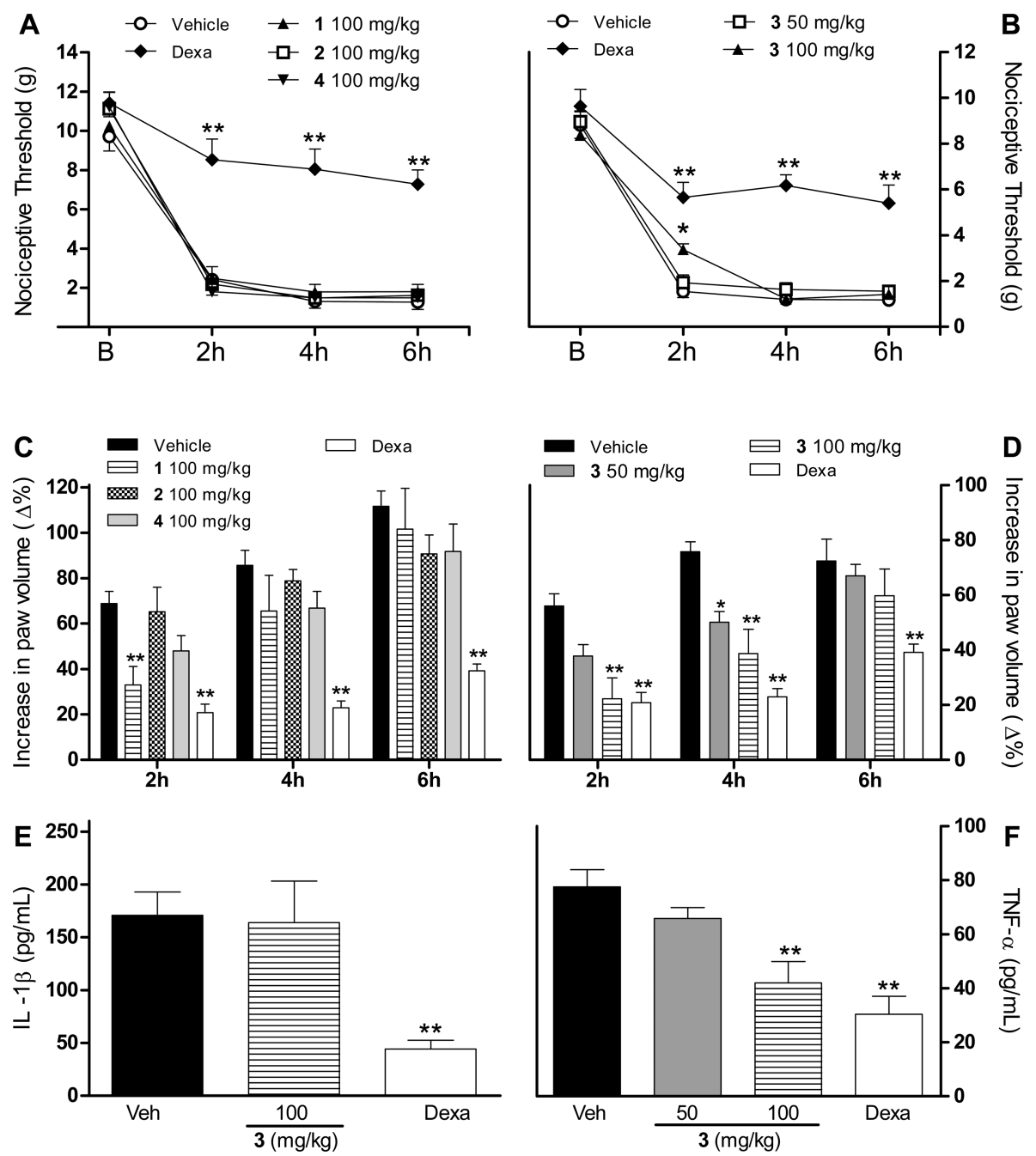

Figure 4. Effects of 1-4 treatment on complete Freund's adjuvant (CFA)-induced paw inflammation. Mice were injected with 1, 2, or 4 (100 mg/kg), 3 $(50$ and $100 \mathrm{mg} / \mathrm{kg}$ ), vehicle (Veh, $5 \%$ DMSO in saline; control group), or dexamethasone (Dexa; $2 \mathrm{mg} / \mathrm{kg}$; positive control) by ip route $40 \mathrm{~min}$ before CFA (injected at time zero). (A and B) Inflammatory hyperalgesia measured at 2, 4, and $6 \mathrm{~h}$ after the CFA stimulus. (C and D) Paw edema measured at 2,4 , and $6 \mathrm{~h}$ after the CFA injection. Edema value was represented as percentage of increase in paw volume. (E and F) Paw interleukin- $1 \beta$ (IL-1 $\beta$ ) and tumor necrosis factor- $\alpha$ (TNF- $\alpha$ ) levels, respectively, determined in skin tissue samples by ELISA, $3 \mathrm{~h}$ after the CFA injection. The results are expressed as picograms of cytokine per milliliter of protein solution. Data are expressed as means \pm SEM; $n=6$ mice per group. *Significantly different from the control group $(p<0.05)$; **significantly different from the control group $(p<0.01)$. Two-way ANOVA followed by Bonferroni's test.

4 or $6 \mathrm{~h}$, after the stimulus (Figure 4B). The pretreatment with 1, 2, and 4 did not produce an antinociceptive effect in the CFA-induced inflammatory pain (Figure 4A). It is important to mention that pretreatment with any of the physalins tested did not alter the baseline nociceptive threshold of the animals (not shown in Figure 4). The pretreatment with 3 (50 and $100 \mathrm{mg} / \mathrm{kg}$, ip) significantly reduced paw edema 2 and $4 \mathrm{~h}$ post- stimulus (Figure 4D), while the antiedematogenic effect of 1 (100 mg/kg, ip) was observed only $2 \mathrm{~h}$ after the stimulus (Figure $4 \mathrm{C}$ ). The pretreatment with $\mathbf{2}$ and $\mathbf{4}$ did not evoke an antiedematogenic 

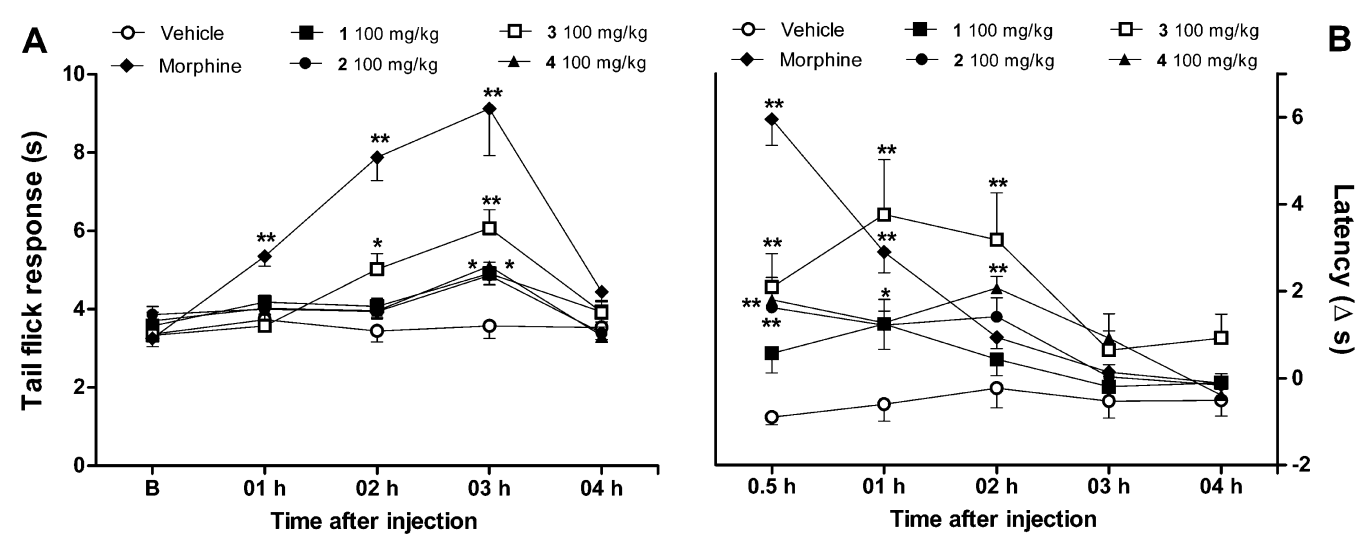

Figure 5. Effects of 1-4 treatment on tail flick and hot plate tests in mice. Panels representing the tail flick response in seconds $(\mathrm{A})$ and the latency $(\Delta)$ in seconds in the hot plate test (B) after ip injection of 1-4 (100 mg/kg), vehicle (5\% DMSO in saline; control group), or morphine (5 mg/kg; positive control). The tail flick baseline (B) is represented in panel A. Data are reported as means $\pm S E M ; n=6$ mice per group. *Significantly different from the control group $(p<0.05)$; **significantly different from the control group $(p<0.01)$. Two-way ANOVA followed by Bonferroni's test.

effect in the CFA model (Figure 4C). The results obtained with control groups support the observed effects for physalins, as vehicle treatment ( $5 \%$ DMSO in saline) yielded no activity; however the positive control, dexamethasone $(2 \mathrm{mg} / \mathrm{kg})$, inhibited CFA-induced hyperalgesia and edema at all time points evaluated (Figure 4). The paw levels of TNF- $\alpha$ (Figure 4F), but not of IL-1 $\beta$ (Figure $4 \mathrm{E}$ ), were reduced by 3 at $100 \mathrm{mg} / \mathrm{kg}$. As expected, dexamethasone ( $2 \mathrm{mg} / \mathrm{kg}$, ip) reduced both the TNF- $\alpha$ and IL-1 $\beta$ paw levels in the CFA model. Consistent with the present data, Vieira et al. (2005) reported that $\mathbf{1}$ and 3 prevented the increase in vascular permeability in a model of intestinal ischemia and reperfusion injury. ${ }^{22}$ This property can contribute to the antiedematogenic effect of $\mathbf{1}$ and $\mathbf{3}$, as described in the present study. In fact, oral treatment with 3 decreased the paw edema and joint inflammation in arthritic mice. ${ }^{23}$ In addition, the inhibitory effect of 3 on TNF- $\alpha$ production has been previously reported. ${ }^{22}$

Data presented here from the CFA test showed that 3 induced a consistent anti-inflammatory effect, while $\mathbf{1}$ induced a discrete effect, and $\mathbf{2}$ and $\mathbf{4}$ presented no anti-inflammatory effect. On the other hand, a consistent antinociceptive effect was demonstrated on writhing and formalin tests following treatment with 1-4 at a smaller range of doses $(25$ and $50 \mathrm{mg} / \mathrm{kg})$. These results suggested that the antinociceptive effect of physalins is due, at least in part, to a specific analgesic action. In order to investigate this hypothesis, the antinociceptive properties of physalins were evaluated using the tail flick and hot plate tests, which mainly identify central analgesics. ${ }^{35}$ The ip administration of $3(100 \mathrm{mg} / \mathrm{kg})$ enhanced the reaction time in the tail flick test, an effect that lasted $3 \mathrm{~h}$ (Figure 5A). Pretreatment with 1 and $4(100 \mathrm{mg} / \mathrm{kg})$ produced an antinociceptive effect on the tail flick test $3 \mathrm{~h}$ after administration. The administration of morphine $(5 \mathrm{mg} / \mathrm{kg}$ ip), the reference drug, resulted in a significant increase in the latency response, with a duration of $3 \mathrm{~h}$ postadministration (Figure 5A). The thermal model of the tail flick test is considered to be a spinal reflex, but may also involve higher neural structures. ${ }^{35,36}$ These characteristics from this model are helpful tools to investigate the site of action of antinociceptive agents. Additionally, from a pharmacological point of view, there is a consensus that this test is truly efficient only for revealing the activity of centrally acting analgesics. ${ }^{35}$ On the basis of this theory, it is possible to propose that physalins possess centrally mediated antinociceptive action. Reinforcing this idea are the present data that physalins exhibited antinociceptive activity on the hot plate test. The hot plate test produces two behavioral components that can be measured in terms of their reaction times, namely, paw licking and jumping. Both are considered to be supraspinally integrated responses. ${ }^{35}$ Intraperitoneal administration of $\mathbf{3}$ and $\mathbf{4}(100 \mathrm{mg} / \mathrm{kg})$ enhanced the latency time in the hot plate test $0.5,1$, and $2 \mathrm{~h}$ after treatment (Figure 5B). Pretreatment with $2(100 \mathrm{mg} / \mathrm{kg})$ produced an antinociceptive effect on the hot plate test at $0.5 \mathrm{~h}$ following administration. Morphine ( $5 \mathrm{mg} / \mathrm{kg}$ ip) caused a significant increase in the latency time until $1 \mathrm{~h}$ after administration (Figure 5B). This test demonstrated the antinociceptive effects of $\mathbf{3}$ and $\mathbf{4}$, which were longer-lasting when compared to morphine, used as the gold standard for the development of new analgesic drugs.

While the pharmacological properties of physalins have been shown in several in vivo and in vitro assays, to the best of our knowledge, this is the first report of its antinociceptive effect. The results from this study show that $\mathbf{1 - 4}$ possess consistent antinociceptive effects and indicate that they are likely due to a supraspinal process, rather than a peripheral site of action.

\section{EXPERIMENTAL SECTION}

General Experimental Procedures. Experiments were performed on male Swiss Webster mice obtained from the Animal Facilities at the Centro de Pesquisas Gonçalo Moniz (Salvador, Brazil). Animals $(22-28 \mathrm{~g})$ were housed in temperature-controlled rooms $\left(22-25^{\circ} \mathrm{C}\right)$, under a 12:12 h light-dark cycle, with access to water and food ad libitum until experimental initiation. All behavioral tests were performed between 8:00 A.M. and 5:00 P.M., and animals were used only once. Animal care and handling procedures were in accordance with International Association for the Study of Pain guidelines for the use of animals in pain research and the Institutional Animal Care and Use Committee FIOCRUZ L-IGM-012/09. ${ }^{37}$ Every effort was made to minimize the number of animals used and any discomfort. Behavioral tests were performed without knowing to which experimental group each mouse belonged. Results shown are from two independent experiments performed.

Physalins B (1), D (2), F (3), and G (4) were isolated from the stems of Physalis angulata collected in December 2006 in Belém do Pará Brazil. The plant was identified by Dr. Lucia Carvalho from the Botanical Garden of Rio de Janeiro. A voucher specimen is held under number RFA $23907 / 8$ at the Federal University of Rio de Janeiro, Brazil, as described previously. ${ }^{18}$

The procedure used for physalin purification has been described. ${ }^{17}$ The percent purity of 1-4 used in the biological experiments carried out was greater than $97 \%$, as determined by HPLC.

Indomethacin, dexamethasone, complete Freund's adjuvant, phosphate-buffered saline (PBS), Tween 20, phenylmethylsulfonyl fluoride (PMSF), benzamethonium chloride, EDTA, aprotinin A, Dulbecco's modified Eagle's medium (DMEM), and 3,3',5,5'-tetramethylbenzidine 
(TMB) were obtained from Sigma Chemical Company (St. Louis, MO, USA). Diazepam and morphine were obtained from Cristália (Itapira, SP, Brazil). Gentamycin was obtained from Novafarma (Anápolis, GO, Brazil). Indomethacin was dissolved in $0.1 \mathrm{M}$ Tris $\mathrm{HCl} \mathrm{pH} 8.0$ plus saline. Dexamethasone was dissolved in ethanol ( $10 \%$ in normal saline). Compounds 1-4 were dissolved in 5\% DMSO plus saline, and the remaining substances were dissolved directly in saline. Drugs were administrated by intraperitoneal or intraplantar routes, and the control group received only vehicle.

Writhing Test. The ip antinociceptive doses of physalins were determined in mice using the writhing test. Acetic acid $(0.8 \% \mathrm{v} / \mathrm{v}$, $10 \mathrm{~mL} / \mathrm{kg}$ ) was injected into the peritoneal cavities of mice, which were placed in a large glass cylinder, and the intensity of nociceptive behavior was quantified by counting the total number of writhes occurring between 0 and 30 min after a stimulus injection. ${ }^{29}$ The writhing response consists of abdominal muscle contraction together with hind limb stretching. Antinociceptive activity was expressed as writhing scores over $30 \mathrm{~min}$. Mice were treated with physalins, vehicle (5\% DMSO in saline; control group), or indomethacin (positive control), by ip route, $40 \mathrm{~min}$ prior to acetic acid exposure.

Formalin Test. Mice were placed in an open Plexiglas observation chamber for $30 \mathrm{~min}$ to acclimate to their surroundings and then removed for formalin administration. Mice were gently restrained while $20 \mu \mathrm{L}$ of $2.5 \%$ formalin (1:100 dilution of stock formalin solution, $37 \%$ formaldehyde in $0.9 \%$ saline) was administered subcutaneously (sc) to the dorsum of the hind paw using a 30-gauge needle. Following injection, mice were returned to the observation chamber for a $30 \mathrm{~min}$ observation period. A mirror was placed behind the chamber to enable unhindered observation of the formalin-injected paw. Mice were observed from 0 to $10 \mathrm{~min}$ (early phase) and from 10 to $30 \mathrm{~min}$ (late phase), and a nociception score was determined for each period by counting the time that the animal spent licking the injected limb during the observation time. ${ }^{38}$ Mice were treated with physalins, vehicle (5\% DMSO in saline; control group), indomethacin (positive control), or morphine (positive control) by ip route $40 \mathrm{~min}$ before formalin administration.

Inflammatory Pain Model. Mice were lightly anesthetized with halothane and received $20 \mu \mathrm{L}$ of complete Freund's adjuvant $(1 \mathrm{mg} / \mathrm{mL}$ of heat-killed Mycobacterium tuberculosis in $85 \%$ paraffin oil and 15\% mannide monoleate) sc in the plantar region of the right hind paw, according to a previously reported method. ${ }^{39}$ Inflammatory hyperalgesia, edema, and local cytokine levels were measured by von Frey filaments, plesthismometer, and ELISA, respectively, as described below. Mice were injected with physalins, vehicle (5\% DMSO in saline; control group), or dexamethasone (positive control) by ip route $40 \mathrm{~min}$ before ip injection of CFA.

Inflammatory Hyperalgesia Evaluation. The threshold to mechanical stimulation was measured with von Frey filaments (Stoelting, Chicago, IL, USA). In a quiet room, mice were placed in acrylic cages $(12 \times 10 \times 17 \mathrm{~cm})$ with wire grid floors $30 \mathrm{~min}$ before the beginning of the test. This consisted of evoking a hind paw flexion reflex with one of a series of filaments with logarithmically incremental stiffness $(0.0045-28.84 \mathrm{~g})$. A positive response was characterized by the removal of the paw followed by clear flinching movements. A tilted mirror placed under the grid provided a clear view of the hind paws of the mice. An up-down method was used to record the threshold. ${ }^{40}$

Plesthismometer Test. The volume of each mouse paw was measured with a plesthismometer (Ugo Basile, Comerio, Italy) before $\left(V_{\mathrm{o}}\right)$ and after $\left(V_{\mathrm{T}}\right)$ the ip CFA injection, as described previously. ${ }^{41}$ The amount of paw swelling was determined for each mouse, and data were represented as the increase in paw volume $(\Delta \%)$.

Cytokine Measurement by ELISA. The paw levels of cytokines were determined as previously described by Lima et al. (2013). ${ }^{42}$ Mice were injected with physalins, vehicle (5\% DMSO in saline; control group), or dexamethasone (positive control) by ip route $40 \mathrm{~min}$ before the CFA injection. Skin tissues were removed from the paws $2 \mathrm{~h}$ after CFA in mice terminally anesthetized with halothane from each experimental group. Tissue proteins were extracted from $100 \mathrm{mg}$ tissue/mL PBS to which $0.4 \mathrm{M} \mathrm{NaCl}, 0.05 \%$ Tween 20 , and protease inhibitors (0.1 mM PMSF, $0.1 \mathrm{mM}$ benzethonium chloride, $10 \mathrm{mM}$
EDTA, and $20 \mathrm{KI}$ aprotinin $\mathrm{A} / 100 \mathrm{~mL}$ ) were added. The samples were centrifuged for $10 \mathrm{~min}$ at $3000 \mathrm{~g}$, and the supernatant was frozen at $-70{ }^{\circ} \mathrm{C}$ for later quantification. Interleukin $1 \beta$ (IL-1 $\beta$ ) and tumor necrosis factor $\alpha$ (TNF- $\alpha$ ) levels were estimated using commercially available immunoassay ELISA kits for mice (R\&D System, Minneapolis, MN, USA), according to the manufacturer's instructions. The results are expressed as pg of cytokine per $\mathrm{mL}$ of protein solution.

Tail Flick Test. The tail flick test in mice was conducted as described elsewhere. ${ }^{43}$ The day before the experiment, each animal was habituated to the restraint cylinder for $20 \mathrm{~min} /$ day for 5 consecutive days. On the day of the experiment, mice were placed in the restraint cylinder, and the tail tip $(2 \mathrm{~cm})$ was submerged in a water bath at $48 \pm 0.5^{\circ} \mathrm{C}$. The latency of the tail withdrawal reflex was measured. Each submersion was terminated after $10 \mathrm{~s}$ to minimize potential skin damage. Tail flick latency was measured before (baseline) and after treatments. Mice were injected with physalins, vehicle (5\% DMSO in saline; control group), or morphine (positive control) by ip route.

Hot Plate Test. The hot plate test in mice was conducted as described elsewhere, with minor modifications. ${ }^{44}$ On the experiment day, mice were placed on the equipment (TECA Corporation, Chicago, IL, USA), which was maintained at $55 \pm 1{ }^{\circ} \mathrm{C}$, and the reaction time in seconds (nociceptive thermal threshold) was noted by observing either the licking of the hind paws or jumping. The threshold was measured before $\left(T_{\mathrm{o}}\right.$; baseline $)$ and after $\left(T_{\mathrm{t}}\right)$ treatments. Data are represented as the difference between $T_{\mathrm{o}}$ and $T_{\mathrm{t}}$. The cutoff time used to prevent skin damage was $10 \mathrm{~s}$. Mice were injected with physalins, vehicle (5\% DMSO in saline; control group), or morphine (positive control) by ip route.

Motor Function Assays. To evaluate possible nonspecific musclerelaxant or sedative effects of physalins, mice were submitted to the rotarod test, as previously described. ${ }^{45}$ The rota-rod apparatus (Insight, Ribeirão Preto, SP, Brazil) consisted of a bar with a diameter of $3 \mathrm{~cm}$, subdivided into five compartments. The bar rotated at a constant speed of $8 \mathrm{rpm}$ The animals were selected $24 \mathrm{~h}$ previously by eliminating those mice that did not remain on the bar for two consecutive periods of $120 \mathrm{~s}$. Animals were treated with diazepam $(10 \mathrm{mg} / \mathrm{kg}$, ip), physalins $(100 \mathrm{mg} / \mathrm{kg}$, ip), or vehicle and, $40 \mathrm{~min}$ afterward, were placed on a rotating rod. The resistance to falling was measured for up to $120 \mathrm{~s}$. The results are expressed as the average time (s) the animals remained on the rotarod in each group. To assess the possible effects of physalins on locomotor activity, mice were evaluated in an open-field test, as described by Lima et al. (2013). ${ }^{46}$ Mice were treated with diazepam $(10 \mathrm{mg} / \mathrm{kg}$, ip), physalins $(100 \mathrm{mg} / \mathrm{kg}$, ip), or vehicle and, $40 \mathrm{~min}$ afterward, were placed individually in a wooden box $(40 \times 60 \times 50 \mathrm{~cm})$ with the floor divided into 12 squares. The number of squares crossed with the four paws was measured for a period of $3 \mathrm{~min}$.

Statistical Analysis. Data are presented as means \pm standard error of the means (SEM) of measurements made on six to nine animals in each group. Comparisons between three or more treatments were made using one-way ANOVA with Tukey's posthoc test or, for repeated measures, two-way ANOVA with Bonferroni's posthoc test, as appropriate. All data were analyzed using Prism 4 Computer Software (GraphPad, San Diego, CA, USA). Statistical differences were considered to be significant at $p<0.05$.

\section{AUTHOR INFORMATION}

\section{Corresponding Author}

*Tel: +55-71-31762260. Fax: +55-71-31762272. E-mail: cfv@ ufba.br.

\section{Notes}

The authors declare no competing financial interest.

\section{ACKNOWLEDGMENTS}

This work was supported by grants from Fundação de Amparo à Pesquisa do Estado da Bahia (FAPESB - PNX0009/2009), FIOCRUZ, and Conselho Nacional de Pesquisa (CNPq). 


\section{REFERENCES}

(1) McGreevy, K.; Bottros, M. M.; Raja, S. N. Eur. J. Pain 2011, 5, 365372.

(2) Debono, D. J.; Hoeksema, L. J.; Hobbs, R. D. J. Am. Osteopath. Assoc. 2013, 113, 620-627.

(3) Breivik, H.; Borchgrevink, P. C.; Allen, S. M.; Rosseland, L. A.; Romundstad, L.; Breivik Hals, E. K.; Kvarstein, G.; Stubhaug, A. Br. J. Anaesth. 2008, 101, 17-24.

(4) O'Connor, A. B. Pharmacoeconomics 2009, 27, 95-112.

(5) White, A. P.; Arnold, P. M.; Norvell, D. C.; Ecker, E.; Fehlings, M. G. Spine (Philadelphia, PA, 1976) 2011, 36, S131-143.

(6) Boyle, J.; Eriksson, M. E.; Gribble, L.; Gouni, R.; Johnsen, S.; Coppini, D. V.; Kerr, D. Diabetes Care 2012, 35, 2451-2458.

(7) Kozma, C. M.; Benson, C.; Slaton, T. L.; Kim, M. S.; Vorsanger, G. J. Curr. Med. Res. Opin. 2012, 28, 1485-1496.

(8) Zin, C. S.; Nissen, L. M.; O'Callaghan, J. P.; Duffull, S. B.; Smith, M. T.; Moore, B. J. J. Pain 2010, 11, 462-471.

(9) Zychowska, M.; Rojewska, E.; Przewlocka, B.; Mika, J. Pharmacol. Rep. 2013, 65, 1601-1610.

(10) Finnerup, N. B.; Sindrup, S. H.; Jensen, T. S. Pain 2010, 150, 573-581.

(11) Borsook, D.; Becerra, L. R. Mol. Pain 2006, 2, 30.

(12) Dworkin, R. H.; O’Connor, A. B.; Audette, J.; Baron, R.; Gourlay, G. K.; Haanpaa, M. L.; Kent, J. L.; Krane, E. J.; Lebel, A. A.; Levy, R. M.; Mackey, S. C.; Mayer, J.; Miaskowski, C.; Raja, S. N.; Rice, A. S.; Schmader, K. E.; Stacey, B.; Stanos, S.; Treede, R. D.; Turk, D. C.; Walco, G. A.; Wells, C. D. Mayo Clin. Proc. 2010, 85, S3-14.

(13) Corrêa, P. M. Diccionario das Plantas Uteis do Brasil; Directoria Geral de Estatística: Rio de Janeiro, 1926; pp 408-409.

(14) Lin, Y. S.; Chiang, H. C.; Kan, W. S.; Hone, E.; Shih, S. J.; Won, M. H. Am. J. Chin. Med. 1992, 20, 233-243.

(15) Bastos, G. N. T.; Santos, A. R. S.; Ferreira, V. M. M.; Costa, A. M. R.; Bispo, C. I.; Silveira, A. J. A.; do Nascimento, J. L. M. J. Ethnopharmacol. 2006, 103, 241-245.

(16) Bastos, G. N. T.; Silveira, A. J. A.; Salgado, C. G.; Picanco-Diniz, D. L. W.; do Nascimento, J. L. M. J. Ethnopharmacol. 2008, 118, 246251.

(17) Soares, M. B. P.; Bellintani, M. C.; Ribeiro, I. M.; Tomassini, T. C. B.; Ribeiro-dos-Santos, R. Eur. J. Pharmacol. 2003, 459, 107-112.

(18) Soares, M. B. P.; Brustolim, D.; Santos, L. A.; Bellintani, M. C.; Paiva, F. P.; Ribeiro, Y. M.; Tomassini, T. C. B.; Ribeiro-dos-Santos, R. Int. Immunopharmacol. 2006, 6, 408-414.

(19) Ji, L.; Yuan, Y.; Luo, L.; Chen, Z.; Ma, X.; Ma, Z.; Cheng, L. Steroids 2012, 77, 441-447.

(20) Pinto, N. B.; Morais, T. C.; Carvalho, K. M.; Silva, C. R.; Andrade, G. M.; Brito, G. A.; Veras, M. L.; Pessoa, O. D.; Rao, V. S.; Santos, F. A. Phytomedicine 2010, 17, 740-743.

(21) Jacobo-Herrera, N. J.; Bremner, P.; Marquez, N.; Gupta, M. P.; Gibbons, S.; Muñoz, E.; Heinrich, M. J. Nat. Prod. 2006, 69, 328-331.

(22) Vieira, A. T.; Pinho, V.; Lepsch, L. B.; Scavone, C.; Ribeiro, I. M.; Tomassini, T.; Ribeiro-dos-Santos, R.; Soares, M. B.; Teixeira, M. M.; Souza, D. G. Br. J. Pharmacol. 2005, 146, 244-251.

(23) Brustolim, D.; Vasconcelos, J. F.; Freitas, L. A.; Teixeira, M. M.; Farias, M. T.; Ribeiro, Y. M.; Tomassini, T. C.; Oliveira, G. G.; Pontesde-Carvalho, L. C.; Ribeiro-dos-Santos, R.; Soares, M. B. J. Nat. Prod. 2010, 73, 1323-1326.

(24) Ferreira, S. H.; Lorenzetti, B. B.; Bristow, A. F.; Poole, S. Nature 1988, 334, 698-700.

(25) Faccioli, L. H.; Souza, G. E.; Cunha, F. Q.; Poole, S.; Ferreira, S. H. Agents Actions 1990, 30, 344-349.

(26) Dinarello, C. A. Chest 2000, 118, 503-508.

(27) Geiger, T.; Rordorf, C.; Cosenti-Vargas, A.; Ferrini, P. G.; Widler,

L.; Glatt, M.; Vosbeck, K. J. Rheumatol. 1994, 21, 1992-1997.

(28) Stein, C. Eur. J. Pharmacol. 2013, 716, 179-187.

(29) Collier, H. O.; Dinneen, L. C.; Johnson, C. A.; Schneider, C. Br. J. Pharmacol. Chem. 1968, 32, 295-310.

(30) Hunskaar, S.; Hole, K. Pain 1987, 30, 103-114.

(31) Conti, B.; Tabarean, I.; Andrei, C.; Bartfai, T. Front. Biosci. 2004, 9, 1433-1449.
(32) Cunha, F. Q.; Ferreira, S. H. Adv. Exp. Med. Biol. 2003, 521, 2239.

(33) Duarte, D. B.; Vasko, M. R.; Fehrenbacher, J. C. Current Protocols in Pharmacology 2012, Chapter 5, Unit 5.6. doi: 10.1002/ 0471141755.ph0506s56.

(34) Woolf, C. J.; Allchorne, A.; Safieh-Garabedian, B.; Poole, S. Br. J. Pharmacol. 1997, 121, 417-424.

(35) Le Bars, D.; Gozariu, M.; Cadden, S. W. Pharmacol. Rev. 2001, 53, 597-651.

(36) Jensen, T. S.; Yaksh, T. L. Brain Res. 1986, 363, 99-113.

(37) Zimmermann, M. Pain 1983, 16, 109-110.

(38) de Oliveira, C. M.; Nonato, F. R.; de Lima, F. O.; Couto, R. D.; David, J. P.; David, J. M.; Soares, M. B.; Villarreal, C. F. J. Nat. Prod. 2011, 74, 2062-2068.

(39) Kassuya, C. A.; Silvestre, A. A.; Rehder, V. L.; Calixto, J. B. Eur. J. Pharmacol. 2003, 478, 145-153.

(40) Chaplan, S. R.; Bach, F. W.; Pogrel, J. W.; Chung, J. M.; Yaksh, T. L. J. Neurosci. Meth. 1994, 53, 55-63.

(41) Nonato, F. R.; Santana, D. G.; de Melo, F. M.; dos Santos, G. G.; Brustolim, D.; Camargo, E. A.; de Sousa, D. P.; Soares, M. B.; Villarreal, C. F. Int. Immunopharmacol. 2012, 14, 779-784.

(42) Lima, M. d. S.; Quintans-Júnior, L. J.; de Santana, W. A.; Kaneto, C. M.; Soares, M. B.; Villarreal, C. F. Eur. J. Pharmacol. 2013, 699, 112117.

(43) dos Santos, G. G. L.; Silva, L. L. C.; Soares, M. B. P.; Villarreal, C. F. Toxicon 2012, 60, 1005-1012.

(44) Long-Chuan, Y.; Hansson, P.; Lundeberg, S.; Lundeberg, T. Eur. J. Pharmacol. 1998, 347, 275-282.

(45) Gama, K. B.; Quintans, J. S.; Antoniolli, A. R.; Quintans-Júnior, L. J.; Santana, W. A.; Branco, A.; Soares, M. B.; Villarreal, C. F. J. Nat. Prod. 2013, 76, 559-563.

(46) de Lima, F. O.; Alves, V.; Barbosa Filho, J. M.; Almeida, J. R.; Rodrigues, L. C.; Soares, M. B.; Villarreal, C. F. Phytother. Res. 2013, 27, 1557-1563. 